Research Paper

\title{
Stem Cells from Cryopreserved Human Dental Pulp Tissues Sequentially Differentiate into Definitive Endoderm and Hepatocyte-Like Cells in vitro
}

Young-Jin Han ${ }^{1}$, Young-Hoon Kang1, 2 , Sarath Belame Shivakumar ${ }^{3}$, Dinesh Bharti ${ }^{3}$, Young-Bum Son ${ }^{3}$ Yong-Ho Choi ${ }^{3}$, Won-Uk Park ${ }^{4}$, June-Ho Byun¹, Gyu-Jin Rho ${ }^{3}$, Bong-Wook Park1, ${ }^{\circledR}$

1. Department of Dentistry, Gyeongsang National University School of Medicine and Institute of Health Science, Jinju, Republic of Korea;

2. Department of Oral and Maxillofacial Surgery, Changwon Gyeongsang National University Hospital, Changwon, Republic of Korea;

3. Department of Theriogenology and Biotechnology, College of Veterinary Medicine and Research Institute of Life Science, Gyeongsang National University, Jinju, Republic of Korea;

4. Department of Dental Technology, Jinju Health College, Jinju, Republic of Korea.

$\square$ Corresponding author: Bong-Wook Park; parkbw@gnu.ac.kr

(c) Ivyspring International Publisher. This is an open access article distributed under the terms of the Creative Commons Attribution (CC BY-NC) license (https://creativecommons.org/licenses/by-nc/4.0/). See http://ivyspring.com/terms for full terms and conditions.

Received: 2017.07.30; Accepted: 2017.10.13; Published: 2017.11.02

\begin{abstract}
We previously described a novel tissue cryopreservation protocol to enable the safe preservation of various autologous stem cell sources. The present study characterized the stem cells derived from long-term cryopreserved dental pulp tissues (hDPSCs-cryo) and analyzed their differentiation into definitive endoderm (DE) and hepatocyte-like cells (HLCs) in vitro. Human dental pulp tissues from extracted wisdom teeth were cryopreserved as per a slow freezing tissue cryopreservation protocol for at least a year. Characteristics of hDPSCs-cryo were compared to those of stem cells from fresh dental pulps (hDPSCs-fresh). hDPSCs-cryo were differentiated into DE cells in vitro with Activin A as per the Wnt3a protocol for 6 days. These cells were further differentiated into HLCs in the presence of growth factors until day 30. hDPSCs-fresh and hDPSCs-cryo displayed similar cell growth morphology, cell proliferation rates, and mesenchymal stem cell character. During differentiation into DE and HLCs in vitro, the cells flattened and became polygonal in shape, and finally adopted a hepatocyte-like shape. The differentiated DE cells at day 6 and HLCs at day 30 displayed significantly increased DE- and hepatocyte-specific markers at the mRNA and protein level, respectively. In addition, the differentiated HLCs showed detoxification and glycogen storage capacities, indicating they could share multiple functions with real hepatocytes. These data conclusively show that hPDSCs-cryo derived from long-term cryopreserved dental pulp tissues can be successfully differentiated into DE and functional hepatocytes in vitro. Thus, preservation of dental tissues could provide a valuable source of autologous stem cells for tissue engineering.
\end{abstract}

Key words: dental pulp, mesenchymal stem cells, cryopreservation, definitive endoderm, hepatocyte.

\section{Introduction}

Several therapeutic strategies for various liver diseases and hepatotoxicity have been explored recently $[1,2]$. One strategy involves the use of stem cells as the source of differentiated hepatocytes. Embryonic stem cells (ESCs), induced pluripotent stem cells (iPSCs), and mesenchymal stem cells (MSCs) derived from various sources have been used for in vitro and in vivo hepatocyte differentiation. The successful induction of functional hepatocytes has been described [3-6].

ESCs and iPSCs have advantages that include higher stemness and pluripotency. They displayed and enhanced potential for differentiation into hepatocytes compared to MSCs. However, drawbacks of ESCs and iPSCs for clinical application in humans include ethical problems, difficulty in isolation and 
cultivation of autologous cells, and economic demerits. MSCs have been the focus as an alternative cell therapy source because of their multipotency, self-renewal, and multi-lineage differentiation potential [1,2]. MSCs from bone marrow and umbilical cord blood were the first to be successfully differentiated into hepatocyte lineage [3]. Subsequently, MSCs derived from various adult tissues, including fat, dental pulp and Wharton's jelly, have been broadly studied for their in vitro hepatocyte differentiation capacity and use as in vivo therapeutic agents for liver diseases [2, 4, 6-10].

Dental tissues, especially the dental follicle, root papilla and dental pulp, obtained from the extracted wisdom teeth have become recognized as a source of stem cells for various tissue engineering applications, such as osteogenic, neurogenic, cardiomyogenic, and hepatogenic regeneration [11-15]. Human dental pulp-derived stem cells (hDPSCs) are self-renewing MSCs that reside in the perivascular niche of the dental pulp of deciduous or permanent teeth [16-18]. Dental pulp is a heterogeneous collection of cells. The pulp originates from the neural crest of the embryo. hDPSCs readily differentiated into mesenchymal-lineage cells (osteocytes, chondrocytes, and adipocytes) and endodermal-lineage cells (hepatocytes and pancreatic cells), as well as neuro-ectodermal cells [6,14, 16, 17, 20, 21, 22]. In addition, hDPSCs displayed remarkable functional hepatogenic differentiation potential in vitro and regeneration of injured liver tissues in vivo [2, 6,18-22].

Varied and different methods have been introduced for the in vitro differentiation of stem cells into hepatocytes. Most rely on growth factors and cytokines related to liver development to boost hepatogenic developmental signals in vitro [4-6, 20, 21]. The use of small molecules has been explored as a replacement for growth factors for a more economical, step-wise, and in vitro hepatogenic induction [23]. Another interesting concept is the necessity of definitive endoderm (DE) as an interphase during endodermal differentiation from stem cells. In this scenario DE is further differentiated into the target endodermal cells, such as hepatocytes or pancreatic cells [24, 25]. This two-step protocol involves the generation of DE from stem cells using Activin A and Wnt3a (Wnt signaling pathway activator) containing medium, followed by the use of an induction cocktail for the differentiation of hepatocytes or pancreatic cells from DE [24, 25]. This two-step induction protocol for the in vitro generation of endodermal cells could be useful in similar developmental steps, such as liver or pancreatic development in vivo, and has proven to be applicable to MSCs from various sources as well as ESCs [23-26]. However, in vitro DE generation from human dental stem cells has not been studied.

We have previously reported the development of a long-term cryopreservation protocol for human dental tissues and Wharton's jelly for use as an autologous stem cell resource [10, 15]. Dental follicle, root apical papilla, and dental pulp tissues from extracted wisdom teeth all have potential value as sources of MSCs. However, the MSCs from these three different dental tissues have different differentiation properties, even when harvested from the same individual $[11,12,14]$. In the present study, hDPSCs were isolated and cultured from the long-term (more than a year) cryopreserved human dental pulp tissues (hDPSCs-cryo). The hDPSCs-cryo were characterized and compared with hDPSCs obtained from fresh dental pulp (hDPSCs-fresh). Finally, hDPSCs-cryo samples were analyzed for their differentiation potential into DE and hepatocyte-like cells (HLCs) in vitro by using the aforementioned two-step protocol.

\section{Materials and Methods}

\section{Chemicals, media, and experimental approval}

All chemicals were purchased from Sigma-Aldrich (St. Louis, MO, USA) and all media were obtained from Gibco (Invitrogen, Grand Island, NY, USA), unless otherwise specified. The $\mathrm{pH}$ of the media was adjusted to 7.4 and the osmolality was adjusted to $280 \mathrm{mOsm} / \mathrm{kg}$. Human dental pulp tissues were harvested from the extracted wisdom teeth of 12 patients (six for tissue cryopreservation and other six for fresh dental pulp harvesting). The patients were similar in age (average, 19 years). All procedures were performed at the Department of Oral and Maxillofacial Surgery at Gyeongsang National University Hospital and Changwon Gyeongsang National University Hospital. All experiments using human dental pulp tissues were approved by Institutional Review Board of Gyeongsang National University Hospital (GNUH IRB-2012-09-004-002). Informed consent was obtained from all patients.

\section{Cryopreservation of human dental pulp tissues and isolation of hDPSCs}

Dental pulp tissues were harvested from the extracted wisdom teeth and cryopreserved as previously described $[13,15]$. Briefly, the dental pulp tissue was separated from the extracted wisdom tooth by using a sterile scalpel and rinsed several times with Dulbecco's phosphate-buffered saline (DPBS) containing $1 \%$ penicillin-streptomycin $(10,000 \mathrm{IU}$ and 10,000 $\mu \mathrm{g} / \mathrm{ml}$, respectively; Pen-Strep). For cryopreservation of dental pulp tissue from six 
donors, the tissue was individually minced into 1-3 $\mathrm{mm}^{2}$ explants and tissue segments and put into a 1.8 $\mathrm{mL}$ cryovial (ThermoScientific, Roskilde, Denmark) containing $1 \mathrm{~mL}$ cryoprotectant $(0.05 \mathrm{M}$ glucose, 0.05 M sucrose, and 1.5 M ethylene glycol: 1900 $\mathrm{mOsm} / \mathrm{kg}$ ). A programmed slow freezing protocol was applied for cryopreservation of cryovials [10, 15]. Briefly, the cryovials were equilibrated for $30 \mathrm{~min}$ at $1^{\circ} \mathrm{C}$, cooled at $-2^{\circ} \mathrm{C} / \mathrm{min}$ to $-9.0^{\circ} \mathrm{C}$, further cooled from $-9.0^{\circ} \mathrm{C}$ to $-9.1^{\circ} \mathrm{C}$ and held for $5 \mathrm{~min}$, further cooled at $-0.3^{\circ} \mathrm{C} / \mathrm{min}$ to $-40^{\circ} \mathrm{C}$, and further cooled at a rate of $-10^{\circ} \mathrm{C} / \mathrm{min}$ to $-140^{\circ} \mathrm{C}$. The cryovials were stored in liquid nitrogen for more than 1 year, after which the cryopreserved dental pulp tissues were thawed by immersion in a circulating water bath at $37^{\circ} \mathrm{C}$ for 1 min.

Fresh dental pulp tissues from the other six donors were rinsed with DPBS containing 1\% Pen-Strep, and individually minced into $1-3 \mathrm{~mm}^{2}$ explants for immediate isolation of hDPSCs. The tissue explants from fresh and cryopreserved dental pulps were treated for isolation and cultivation of hDPSCs as previously reported [13-15]. Briefly, dental pulp was digested by incubating in DPBS containing 1 $\mathrm{mg} / \mathrm{mL}$ collagenase type I at $37^{\circ} \mathrm{C}$ for $40 \mathrm{~min}$ with occasional agitation. The digestion was stopped by adding advanced Dulbecco's modified Eagles medium (ADMEM) supplemented with 10\% fetal bovine serum (FBS). Each sample was mechanically dissociated and filtered through a $40 \mu \mathrm{m}$ nylon cell strainer (BD Falcon, Franklin Lake, NJ, USA) to harvest single cell suspension. Following centrifugation at $500 \times \mathrm{g}$ for $5 \mathrm{~min}$, cell pellets were reconstituted and cultured in ADMEM containing $10 \%$ FBS and 1\% Pen-Strep in a 25 T-flask (Nunc ${ }^{\mathrm{TM}}$, Roskilde, Denmark). Cultures were maintained at $37^{\circ} \mathrm{C}$ in a humidified atmosphere of $5 \% \mathrm{CO}_{2}$ in air with a change of the medium every 3 days. Primary cell cultures were grown until they reached $70-80 \%$ confluence, and then, cells at passage 3 were used for all the experimentation unless otherwise indicated.

\section{Analyses of cell survival and proliferation rates of hDPSCs-fresh and hDPSCs-cryo}

Immediately after isolation of cells from fresh and long-term cryopreserved dental pulp tissues, all cells were stained with propidium iodine (PI; Sigma-Aldrich) and Hoechst 33342 (Sigma-Aldrich), as previously reported [15]. To calculate the cell survival rate in the fresh pulp and cryopreserved pulp, the proportion of PI positive cells (dead cells) in the Hoechst 33342 stained cells (living and dead) were calculated using fluorescent microscopy with an Eclipse Ti-U microscope (Nikon Instrument, Tokyo, Japan) (Figs. 1A \& B).

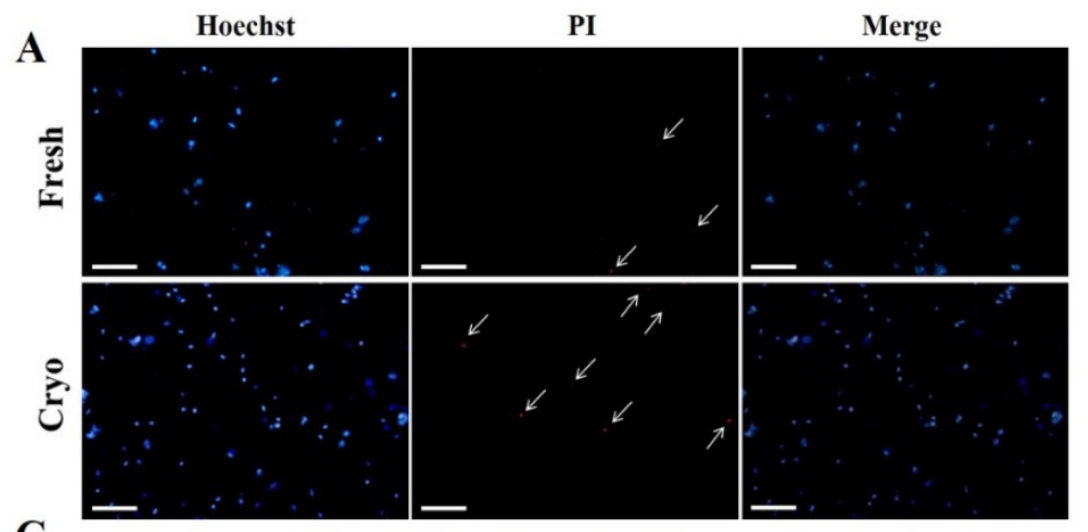

C

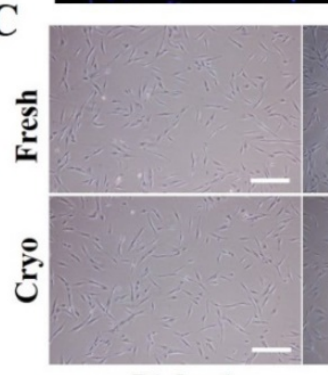

P1 day 1

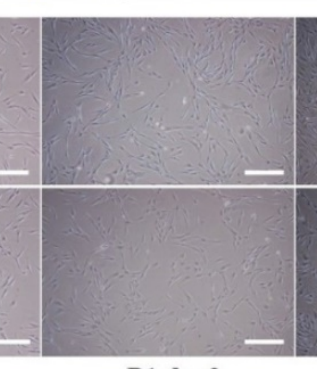

P1 day2

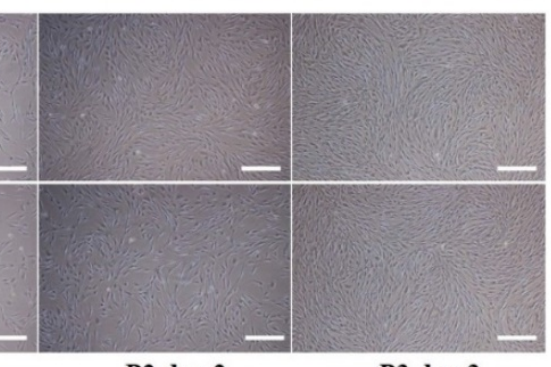

P2 day 2

P3 day 3

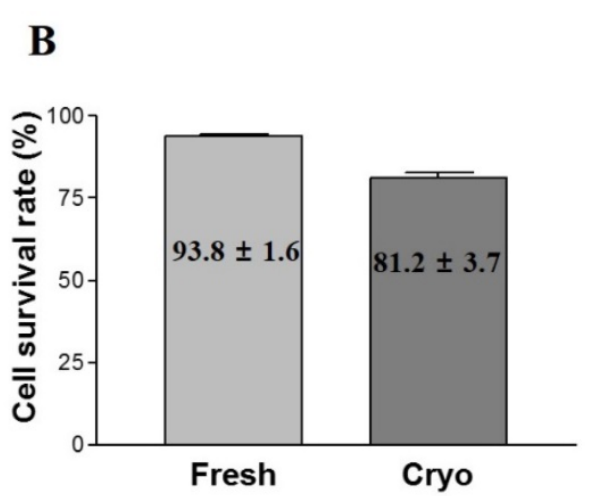

D

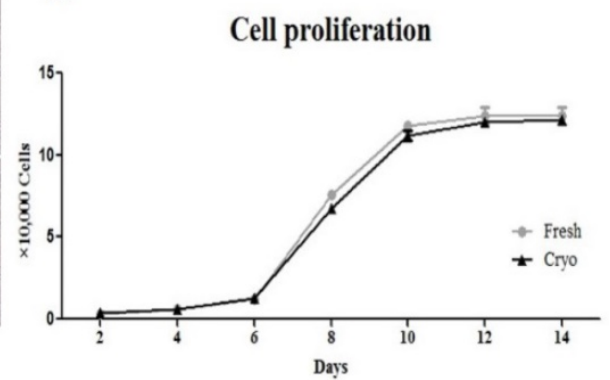

Figure 1. Cell survival rates, morphology, and cell proliferation curves of stem cells from fresh (Fresh) and cryopreserved $($ Cryo $)$ human dental pulp $($ Scale bar $=100$ $\mu \mathrm{m})$. (A) Representative images of Hoechst 33342 (Hoechst) and propidium iodide (PI) staining in isolated single cells from fresh and cryopreserved dental pulp. (B) Cell survival rates were calculated based on PI and Hoechst positive cell ratio in the isolated single cells, which were $93.8 \pm 1.6 \%$ in fresh and $81.2 \pm 3.7 \%$ in cryopreserved dental pulp. (C) Cell morphology of hDPSCs from fresh and cryopreserved dental pulps. The two cell groups showed same culture characteristics with plate adherent fibroblast-like morphology. (D) The cell proliferation rates by population doubling time (PDT) revealed the same curvatures in the two groups. 

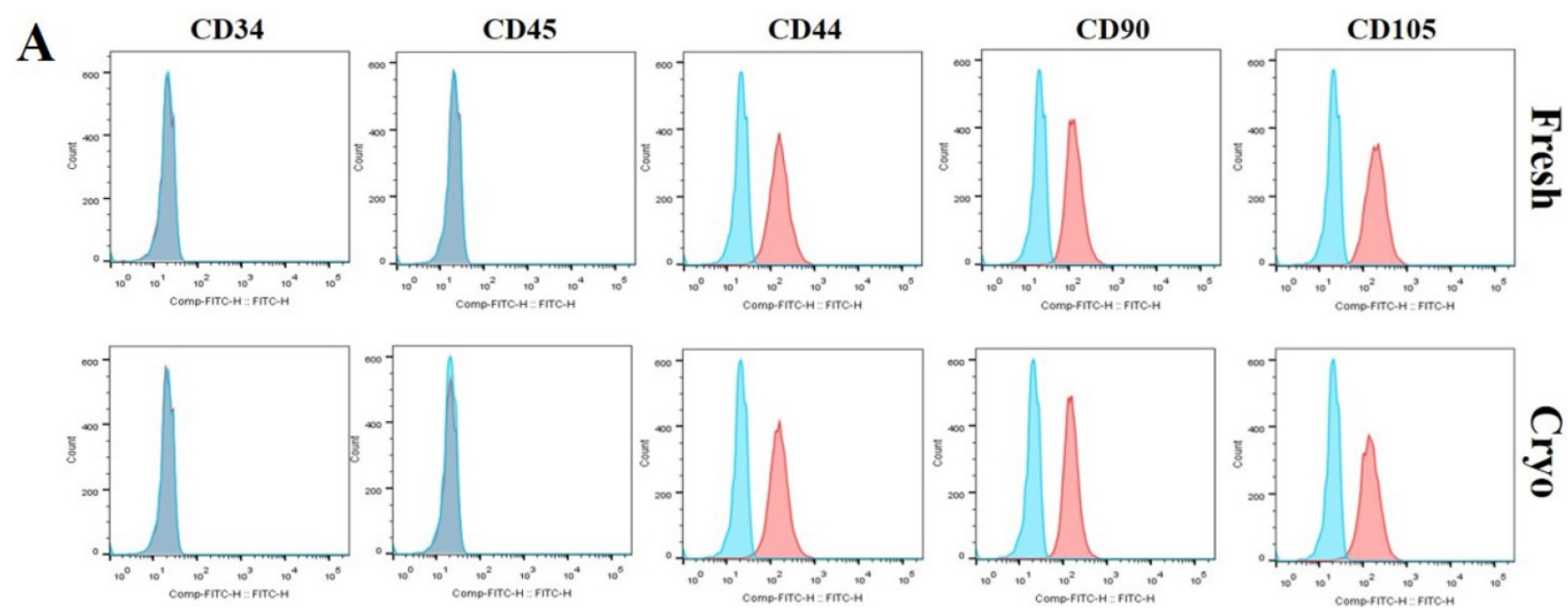

B

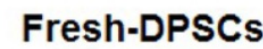

\section{Cryo-DPSCs}
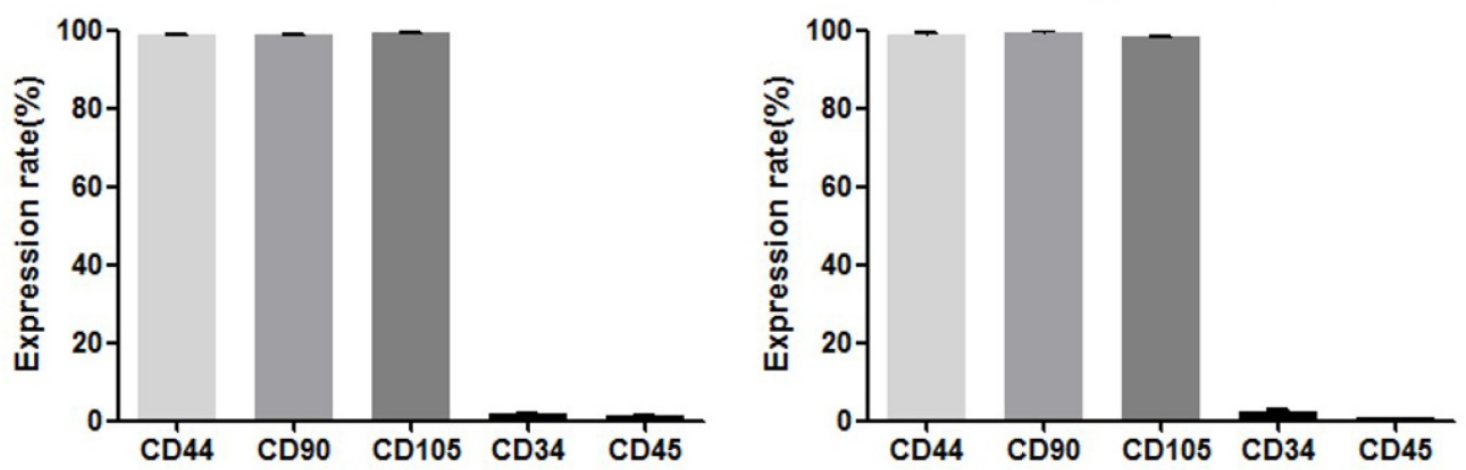

Figure 2. Fluorescence-activated cell sorting (FACS) analysis of $h D P S C s$ from fresh and cryopreserved dental pulps. (A, B) Results of FACS analysis showed almost no expression for hematopoietic markers (CD34 and CD45) but high positive expressions of mesenchymal stem cells markers (CD44, CD90, and CD105).

After their third passage, the morphologies of hDPSCs-fresh and hDPSCs-cryo cells were observed and analyzed through light microscopy and images were taken using a Diaphot 300 apparatus (Nikon Instrument) (Fig. 1C). hDPSCs-fresh and hDPSCs-cryo proliferation rates were analyzed by determining the population doubling time (PDT) as previously described [10]. Briefly, MSCs were seeded at $2 \times 10^{3}$ cells in each well of a 24 -well culture plate in triplicate. Cell number was determined every 2 days for up to 14 days. PDT of MSCs was calculated using the formula $\mathrm{PDT}=t(\log 2) /\left(\log N_{t}-\log N_{0}\right)$, where $t$ represents the culture time, and $N_{0}$ and $N_{t}$ are the initial and final hDPSCs numbers before and after seeding, respectively (Fig. 1D).

\section{Characterization of hDPSCs isolated from fresh and cryopreserved dental pulps}

Expressions of cell surface markers for hematopoietic and MSC marker proteins were analyzed using flow cytometry as previously described [15]. Briefly, hDPSCs-fresh and hDPSCs-cryo were harvested using $0.25 \%$ trypsin-EDTA and fixed in $3.7 \%$ formaldehyde solution. The cells were washed twice with DPBS and labeled with fluorescein isothiocyanate (FITC)-conjugated mouse anti-human CD34 (BD Pharmingen, San Jose, CA, USA), FITC mouse anti-human CD45 (Santa Cruz Biotechnology, Dallas, TX, USA), FITC mouse anti-human CD90 (BD Pharmingen), unconjugated mouse monoclonal CD73 (Santa Cruz Biotechnology), and unconjugated mouse monoclonal IgG 2 a (CD105; Santa Cruz Biotechnology,) for $30 \mathrm{~min}$. Unconjugated primary antibodies were treated with secondary FITC-conjugated goat anti-mouse IgG (BD Pharmingen) for $30 \mathrm{~min}$ in the dark. The isotype control was mouse IgG1 (BD Pharmingen). A total of 15,000 labeled cells per sample were acquired. The results were analyzed using cell Quest Pro software (Becton Dickinson) (Fig. 2).

\section{In vitro differentiation potentials of hDPSCs into mesenchymal lineages}

The in vitro differentiation ability into adipocyte, osteocyte, and chondrocyte lineages was assessed as previously described [10, 12]. Briefly, hDPSCs-fresh and hDPSCs-cryo were cultured in ADMEM 
containing lineage-specific constituents for 21 days with a change to fresh medium every 3 days. The adipogenic medium was composed of $1 \mu \mathrm{M}$ dexamethasone, $10 \mu \mathrm{M}$ insulin, $100 \mu \mathrm{M}$ indomethacin, and $500 \mu \mathrm{M}$ isobutylmethylxanthine (IBMX). Adipogenesis was confirmed based on the accumulation of lipid droplets by staining with Oil red $\mathrm{O}$ solution. The osteogenic medium was composed of $0.1 \mu \mathrm{M}$ dexamethasone, $50 \mu \mathrm{M}$ ascorbate-2-phosphate, and $10 \quad \mathrm{mM}$ glycerol-2-phosphate. Osteogenesis was confirmed via Alizarin Red and Von Kossa staining. The commercial chondrogenic medium (StemPro ${ }^{\circledR}$ Osteocyte/Chondrocyte Differentiation Basal Medium; StemPro ${ }^{\circledR}$ Chondrogenesis supplement, Gibco Life Technologies, Gaithersburg, MD, USA) and differentiation was confirmed via Alcian blue staining (Fig. 3A). Cytochemical staining with Oil red $\mathrm{O}$, Alizarin Red, Von Kossa, and Alcian Blue were conducted as detailed by the manufacturer as previously reported $[10,12,15]$. The in vitro differentiated cells were analyzed for lineage-specific marker expressions by using real-time quantitative PCR (RT-qPCR) (Figs. 3B \& C).

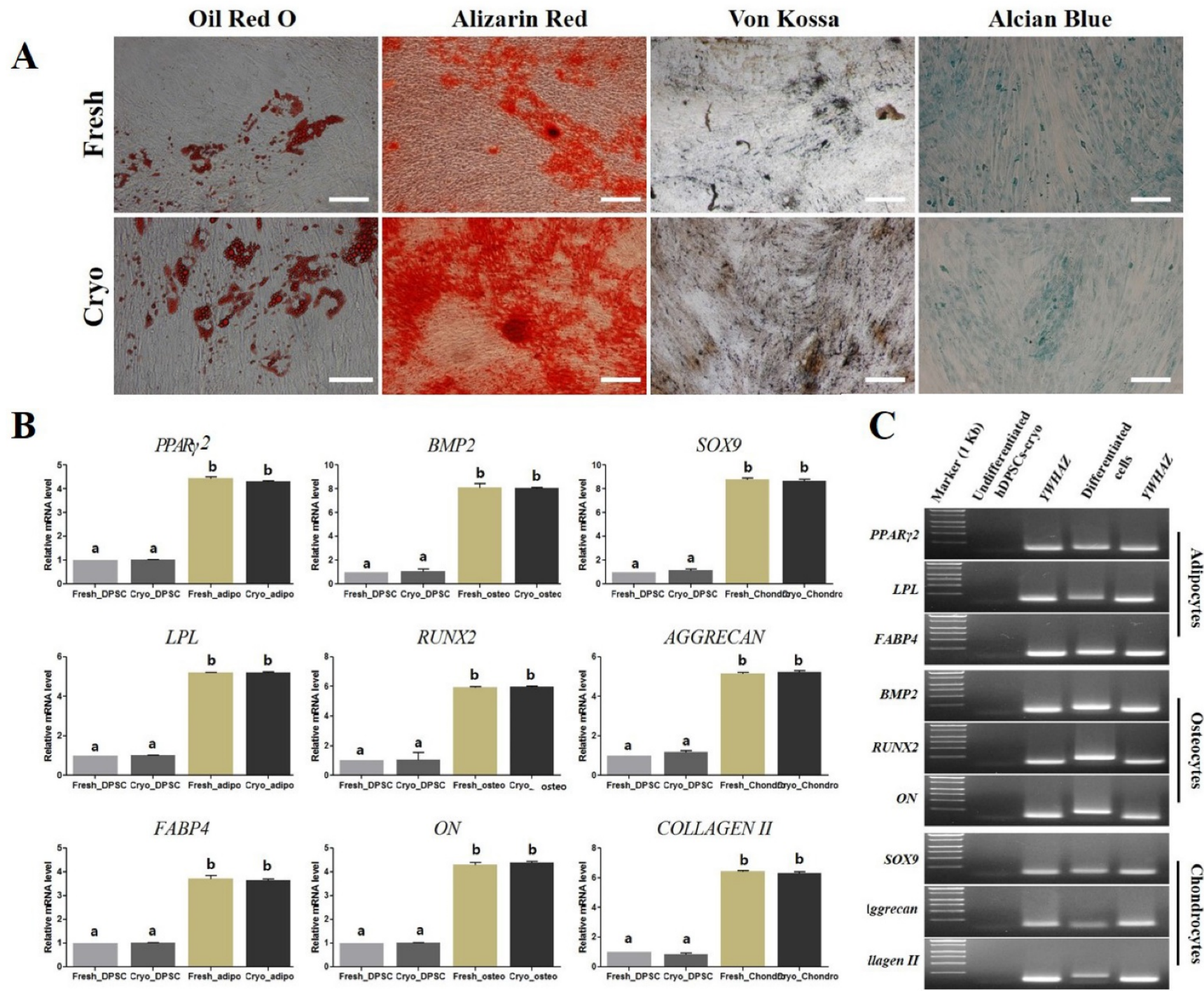

Figure 3. In vitro differentiation of hDPSCs from fresh and cryopreserved dental pulps into mesenchymal lineage cells. (A) hDPSCs from fresh and cryopreserved pulps showed similar in vitro differentiation potential to mesenchymal lineage cells, as confirmed via lineage specific staining (Oil red $O$ for adipocytes, Alizarin Red and Von Kossa for osteocytes, and Alcian Blue for chondrocytes). Scale bar $=100 \mu \mathrm{m}$. (B) mRNA levels of lineage-specific genes were analyzed using real-time PCR (RT-qPCR) with the 2- $\triangle \triangle C_{t}$ method using YWHAZ for normalization and is expressed as the fold-change relative to the control (undifferentiated hDPSCs-cryo). RT-qPCR showed that mRNA levels of lineage-specific genes were highly detected in the differentiated cells compared than undifferentiated hDPSCs (PPARr2, LPL, and FABP4, adipocyte-specific; BMP2, Runx2, and ON, osteocyte-specific; and SOX9, Aggrecan, and Collagen II, chondrocyte-specific). Data represent the mean \pm SD of three independent experiments. Significantly different from control; *, $p<0.05$ (C) Representative images of RT-qPCR products of hDPSCs-cryo group to show product size of (B). Abbreviations: PPARY2, peroxisome proliferator activated receptor- $\mathrm{Y} 2$; LPL, lipoprotein lipase; FABP4, fatty acid binding Protein 4; BMP2, bone morphogenetic protein 2; RUX2, runt-related transcription factor 2; ON, osteonectin; SOX9, sex determining region Y-box 9; Aggrecan, cartilage-specific proteoglycan core protein; Collagen II, type II collagen; YWHAZ, Tyrosine 3-monooxygenease/tryptophan 5-monooxygenease activation protein, zeta polypeptide. 


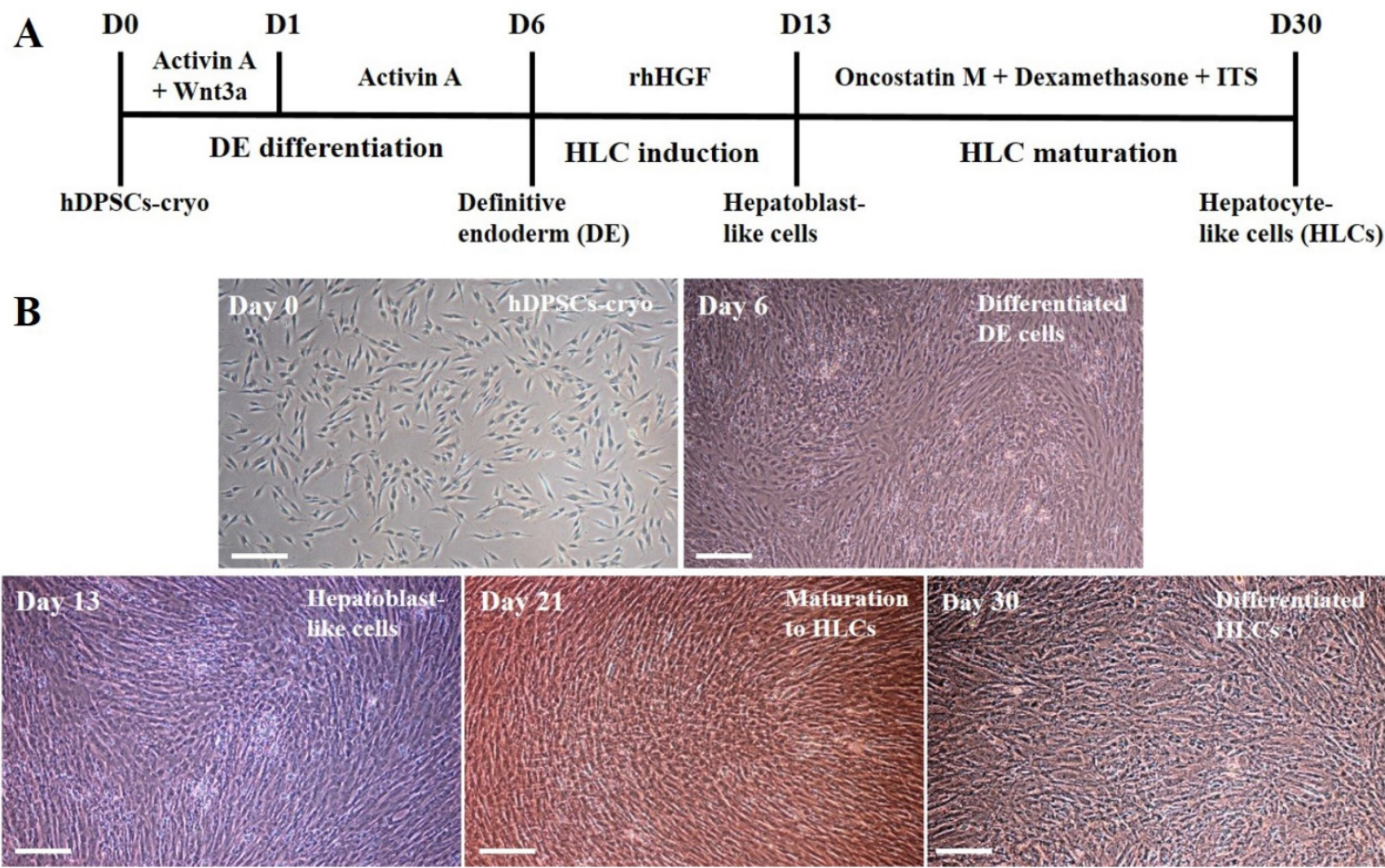

Figure 4. Schematic illustration of differentiation protocol into definitive endoderm and hepatocyte-like cells in vitro and representative image of each differentiated step (Scale bar $=100)$. (A) hDPSCs-cryo were differentiated into DE cells using the Activin A and Wnt3a protocol. Cells were induced to form hepatoblast-like cells with recombinant human hepatocyte growth factor (rhHGF). Finally, the cells were matured with Oncostatin M, dexamethasone, and ITS. The culture data for each step are presented in the illustration. (B) Morphological changes of differentiated cells were presented from hDPSCs-cryo to DE, hepatoblast-like cells, and hepatocyte-like cells. Fibroblast-like cells were gradually flattened, and changed to round or polygonal shape as differentiation time passed. Scale bar $=100 \mu \mathrm{m}$.

\section{In vitro differentiation of hDPSCs-cryo into DE and hepatocyte-like cells}

The hDPSCs-cryo were differentiated into DE cells in vitro as per a previously reported Activin A and Wnt3a protocol $[24,25]$ with minor modification. Briefly, hDPSCs-cryo were harvested at $90 \%$ confluence after passage 3 and seeded at $5 \times 10^{3}$ cells $/ \mathrm{cm}^{2}$ and cultured in ADMEM supplemented with $10 \%$ FBS. After reaching $70 \%$ confluence, the cells were induced into DE by culturing in ADMEM supplemented with $5 \mathrm{ng} / \mathrm{ml}$ Activin A and $50 \mathrm{ng} / \mathrm{ml}$ Wnt3a for $24 \mathrm{~h}$ (D1: culture day 1). The medium was changed to ADMEM supplemented with $5 \mathrm{ng} / \mathrm{ml}$ Activin A for an additional 5 days (D6). A portion of the in vitro induced DE cells was harvested and analyzed for the expressions of the DE markers.

Other induced DE cells were further differentiated into HLCs. The cells were continuously cultured using hepatocyte priming medium composed of ADMEM supplemented with $2 \%$ FBS and $20 \mathrm{ng} / \mathrm{mL}$ recombinant human hepatocyte growth factor (rhHGF: R\&D Systems Inc., Minneapolis, MN, USA) for 7 days (D13). The primed cells were then cultured in hepatocyte maturation medium composed of ADMEM supplemented with $2 \%$ FBS, $10 \mathrm{ng} / \mathrm{mL}$ oncostatin M (R\&D Systems), 10 $\mathrm{nmol} / \mathrm{L}$ dexamethasone, and $1 \%$ insulin-transferrin-selenium mix (ITS-mix) for a further 17 days (D30). All media were changed on alternative days. For comparison, control cultures (hDPSCs-cryo without hepatogenic differentiation) were also maintained in parallel to the differentiation experiments. The differentiated HLCs were harvested and analyzed for the expression of various hepatocyte markers. The schematic in vitro differentiation protocol for DE and HLCs is illustrated in Fig. 4A.

\section{Immunocytochemistry for induced DE and hepatocytes in vitro}

The differentiated DE and HLCs were fixed with $3.7 \%$ formaldehyde for $30 \mathrm{~min}$ and permeabilized with $0.25 \%$ Triton X-100 for $10 \mathrm{~min}$ at $20^{\circ} \mathrm{C}$. Cells were blocked with $1 \%$ bovine serum albumin (BSA) in DPBS for $1 \mathrm{~h}$ prior to incubation of the cells with primary antibodies overnight at $4^{\circ} \mathrm{C}$. For induced DE cells, 1:100 diluted mouse anti-sex determining region Y-box 17 (SOX17) (ab192453, Abcam, Cambridge, UK) and 1:100 diluted rabbit anti-forehead box protein A2 (FOXA2) (ab108422, Abcam) were used. For 
differentiated hepatocyte-like cells, 1:200 diluted goat anti-human albumin (ALB) (sc-46293, Santa Cruz Biotechnology) and 1:200 diluted goat anti-hepatocyte nuclear factor 1-alpha (HNF-1a) (sc-6547, Santa Cruz Biotechnology) were used as primary antibodies. After washing out the unbound primary antibodies, samples were treated with CruzFluor ${ }^{\mathrm{TM}}$ 594-conjugated donkey anti-goat IgG (1:200, Santa Cruz Biotechnology), donkey anti-rabbit IgG (1:200, Santa Cruz Biotechnology), or FITC-conjugated donkey anti-mouse IgG (1:200, Santa Cruz Biotechnology) secondary antibodies for $45 \mathrm{~min}$ at $37^{\circ} \mathrm{C}$. The nuclei of cells were counterstained with 1 $\mu \mathrm{g} / \mathrm{ml}$ 4',6-diamidino-2-phenylindole (DAPI) for 5 min and images were taken using an Eclipse Ti-U fluorescence microscope (Nikon Instrument).

\section{Real-time quantitative polymerase chain reaction ( $R T$-qPCR)}

The expression of lineage-specific genes in the cells differentiated from hDPSCs was evaluated by RT-qPCR in triplicate from three independent experiments. Total RNA was isolated from both control and differentiated cells using RNeasy mini kit (Qiagen, Valencia, CA, USA). A total of $2000 \mathrm{ng}$ of RNA was used to synthesize complementary DNA (cDNA) using Omniscript RT kit (Qiagen) with either random hexamers or oligo-dT primer. The reaction was carried out at $37^{\circ} \mathrm{C}$ for $60 \mathrm{~min}$. Real-time PCR was performed using a Rotor gene Q (Qiagen) and Rotor Gene $^{\mathrm{TM}}$ SYBR green PCR kit (Qiagen). A total of $50 \mathrm{ng}$ cDNA was mixed with 1x SYBR Green mix, $5.5 \mu \mathrm{l}$ RNase free water, and $1 \mu \mathrm{l}$ each of the forward and reverse primers at $400 \mathrm{nM}$ final concentration. The final reaction volume was adjusted to $25 \mu \mathrm{L}$. The assay was carried out with initial denaturation at $95^{\circ} \mathrm{C}$ for 10 min, followed by 40 PCR cycles of $95^{\circ} \mathrm{C}$ for $10 \mathrm{~s}$, $55^{\circ} \mathrm{C}-60^{\circ} \mathrm{C}$ for $6 \mathrm{~s}$, and $72^{\circ} \mathrm{C}$ for $4 \mathrm{~s}$, followed by a melting curve from $60^{\circ} \mathrm{C}$ to $95^{\circ} \mathrm{C}$ at $1{ }^{\circ} \mathrm{C} / \mathrm{s}$ and then cooling at $40^{\circ} \mathrm{C}$ for $30 \mathrm{~s}$, according to the manufacturer's protocol. Ct values and melting curves of each sample were analyzed using Rotor-Gene $\mathrm{Q}$ series software (Qiagen). The relative abundance of the target gene expression was calculated with the 2- $\Delta \Delta \mathrm{Ct}$ method using YWHAZ (tyrosine 3-monooxygenase/tryptophan 5-monooxygenase activation protein, zeta polypeptide) for normalization and is expressed as the fold-change relative to the control (undifferentiated hDPSCs). The detailed information of primers used in the present study is presented in Table 1.

Table 1. List of primers used for evaluating of in vitro differentiations of hDPSCs into mesenchymal lineages, definitive endoderm, and hepatocyte-like cells.

\begin{tabular}{|c|c|c|c|c|}
\hline Gene & Primer Sequence & Product size (bp) & Annealing temp $\left({ }^{\circ} \mathrm{C}\right)$ & Accession no. \\
\hline RUNX2 & $\begin{array}{l}\text { F: ATGTGTGTTTGTTTCAGCAG } \\
\text { R: TCCCTAAAGTCACTCGGTAT }\end{array}$ & 199 & 60 & NM_001024630.3 \\
\hline ON & $\begin{array}{l}\text { F: GTGCAGAGGAAACCGAAGAG } \\
\text { R: AAGTGGCAGGAAGAGTCGAA }\end{array}$ & 202 & 60 & J03040.1 \\
\hline$B M P 2$ & $\begin{array}{l}\text { F: TAGACCTGTATCGCAGGCAC } \\
\text { R: GGTTGTTTTCCCACTCGTTT }\end{array}$ & 149 & 60 & NM_001200.2 \\
\hline PPAR ${ }^{2}$ & $\begin{array}{l}\text { F: TGCTGTCATTATTCTCAGTGGA } \\
\text { R: GAGGACTCAGGGTGGTTCAG }\end{array}$ & 124 & 60 & AB565476.1 \\
\hline FABP4 & $\begin{array}{l}\text { F: TGAGATTTCCTTCATACTGGG } \\
\text { R: TGGTTGATTTTCCATCCCAT }\end{array}$ & 128 & 60 & NM_001442.2 \\
\hline$L P L$ & $\begin{array}{l}\text { F: AGACACAGCTGAGGACACTT } \\
\text { R: GCACCCAACTCTCATACATT }\end{array}$ & 137 & 60 & NM_000237.2 \\
\hline SOX9 & $\begin{array}{l}\text { F: ATGGAGCAGCGAAATCAACG } \\
\text { R: CAAAGTCCAAACAGGCAGAGAG }\end{array}$ & 118 & 60 & ВС007951.2 \\
\hline AGGRECAN & $\begin{array}{l}\text { F: GAATGGGAACCAGCCTATACC } \\
\text { R: TCTGTACTTTCCTCTGTTGCTG }\end{array}$ & 98 & 60 & NM_001135.3 \\
\hline COLLAGEN II & $\begin{array}{l}\text { F: GAGACCTGAAACTCTGCCACC } \\
\text { R: TGCTCCACCAGTTCTTCTTGG }\end{array}$ & 165 & 55 & NM_001844.4 \\
\hline$A F P$ & $\begin{array}{l}\text { F: GCCACTTGTTGCCAACTCAG } \\
\text { R: CTGAAGCATGGCCTCCTGTT }\end{array}$ & 164 & 60 & NM_001134.2 \\
\hline$A L B$ & $\begin{array}{l}\text { F: CAGGCGACCATGCTTTTCAG } \\
\text { R: TTATCGTCAGCCTTGCAGCA }\end{array}$ & 243 & 60 & NM_000477.5 \\
\hline HNF4A & $\begin{array}{l}\text { F: GGAAGTGGCTGAGTCAGGAC } \\
\text { R: CGGAAGCCCCTCAACTTGAT }\end{array}$ & 129 & 55 & NM_178849.2 \\
\hline SOX17 & $\begin{array}{l}\text { F: GTTGTCCTGGGTGTGTTT } \\
\text { R: GACTAGTGTGACAGAGGTACTA }\end{array}$ & 89 & 60 & NM_022454.3 \\
\hline FOXA2 & $\begin{array}{l}\text { F: ACAGAGGGCCACACAGATA } \\
\text { R: GCTTGAAGAAGCAGGAGTCTAC }\end{array}$ & 115 & 55 & ВC006545.2 \\
\hline YWHAZ (reference) & $\begin{array}{l}\text { F: CTTCACAAGCAGAGAGCAAAG } \\
\text { R: CGACAATCCCTTTCTTGTCATC }\end{array}$ & 102 & 55 & NM_003406.3 \\
\hline
\end{tabular}




\section{Urea assay}

Undifferentiated hDPSCs-cryo (control) and differentiated HLCs were incubated in culture medium supplemented with $1 \mathrm{mM}$ ammonium chloride $\left(\mathrm{NH}_{4} \mathrm{Cl}\right)$ for $24 \mathrm{~h}$, respectively. Culture supernatant was collected in each culture group (control vs. HLCs), centrifuged at $300 \times \mathrm{g}$ for $5 \mathrm{~min}$, and urea levels were analyzed using an ELISA kit (Abcam) according to the manufacturer's instructions.

\section{Periodic Acid-Schiff (PAS) staining}

Differentiated hepatocyte-like cells were evaluated for their glycogen storage ability by using PAS staining, as previously reported [10]. Briefly, cells were fixed in $3.7 \%$ formaldehyde for $30 \mathrm{~min}$ and then treated with the oxidizing agent $1 \%$ periodic acid for 5 min at $20^{\circ} \mathrm{C}$ and rinsed three times with distilled water. Cells were further treated with Schiff's reagent for $15 \mathrm{~min}$ at room temperature. Finally, cells were rinsed with distilled water for $10 \mathrm{~min}$ and counter stained with Mayer's hematoxylin for $30 \mathrm{~s}$ and washed with distilled water. Glycogen storage was analyzed under a light microscope (Nikon Diaphot 300).

\section{Statistical analyses}

Independent experiments were repeated at least three times. The data shown are the mean \pm standard deviation (SD). Statistical differences between experimental groups were determined via one-way analysis of variance (ANOVA), followed by Tukey's test for multiple comparisons or an unpaired $t$-test for single comparisons of experimental data relative to the control value using PASW statistics 18 (SPSS Inc., Hong Kong). Differences were considered significant at $p<0.05$. Significant differences are denoted using an asterisk $\left({ }^{*}\right)$.

\section{Results}

\section{Survival rates, morphology, and proliferation rates of hDPSCs from fresh and cryopreserved dental pulps}

Cells were isolated from fresh and cryopreserved dental pulps and their survival rates were measured using PI and Hoechst 33342 staining protocol [15]. The calculated cell survival rates were $93.8 \pm 1.6 \%$ in fresh dental pulps and $81.2 \pm 3.7 \%$ in cryopreserved dental pulps (Figs. 1A \& B). There was no difference in cell morphology between hDPSCs-fresh and hDPSCs-cryo during cell culture. Both displayed a plate-adherent and homogeneous fibroblast-like growth pattern (Fig. 1C). PDT graphs for cell proliferation rates showed similar curvature in two cell groups, indicating the same proliferation rate (Fig. 1D).

\section{Characterization of hDPSCs from fresh and cryopreserved dental pulps}

hDPSCs-fresh and hDPSCs-cryo at passage 3 expressed similarly high levels of MSC-markers (CD44, CD90, and CD105), with almost no expression of hematopoietic markers (CD34 and CD45) as assessed via fluorescence activated cell sorting analysis (Fig. 2). In addition, the two cell groups showed successful in vitro differentiation potential for mesenchymal lineage cells, including osteocytes, adipocytes, and chondrocytes, under the specific induction protocols (Fig. 3A). These differentiated cells also demonstrated similarly increasing of mRNA levels for lineage-specific genes by RT-qPCR comparing with those of non-differentiated hDPSCs (Figs. 3B \& C). These results indicate that stem cells from fresh and cryopreserved dental pulps have same MSC characteristics, consistent with a previous report that detected the same stem cells properties between MSCs from fresh and cryopreserved dental follicles [15].

\section{Differentiation of hDPSCs-cryo into DE and HLCs in vitro}

hDPSCs-cryo at passage 3 were sequentially differentiated into DE and HLCs in vitro using the two-step protocol, which is schematically illustrated in Fig. 4A. At D0 of induction, plate-adherent fibroblast-like cells were mainly observed, but these gradually flattened until D6 (Fig. 4B). The differentiated DE cells at D6 showed significantly increased DE-specific markers, Sox17 and FOXA2, at the mRNA and protein levels (Figs. 5A, C, \& 6A).

The induced DE cells were further differentiated into HLCs under rhHGF for 7 days (until D13) and then maintained in the medium with oncostatin $M$, dexamethasone, and ITS-mix for 17 days (until D30). During the in vitro induction period, the cell morphology further changed to a round or polygonal shape. At D30 of differentiation, the cell morphology was more obviously altered to a hepatocyte-like shape (Fig. 4B). In addition, differentiated HLCs at D30 revealed 4-6 times increased mRNA levels than undifferentiated hDPSCs-cryo for hepatocyte-markers, HNF4A, ALB, and AFP, by RT-qPCR (Figs. 5B \& C). The differentiated HLCs at D30 also revealed abundant protein expressions for ALB and HNF-1a by immunocytochemistry (Fig. 6A). The differentiated HLCs were analyzed for the functional characteristics of hepatocytes with glycogen storage via PAS staining and detoxification based on urea secretion capacity. The culture medium 
of differentiated HLCs showed about 4-5 times higher urea synthesis potential, which were generated in the HLCs for the detoxification response to exogenous ammonia, compared to those of undifferentiated hDPSCs-cryo (Fig. 6B). In PAS staining, significant positive staining of glycogen granules in the cytoplasm of differentiated HLC was observed, whereas a weak PAS staining signal was detected in undifferentiated hDPSCs-cryo (Fig. 6C). These results indicate that hDPSCs-cryo can successfully differentiate to DE cells and can be further induced to functional hepatocyte-like cells.

\section{Discussion}

In our previous studies, dental follicles from extracted wisdom teeth were cryopreserved as per the newly developed tissue cryopreservation protocol [15]. The MSCs from cryopreserved dental follicles possessed an immunomodulatory property and enhanced in vivo osteogenesis [13]. Similarly, the
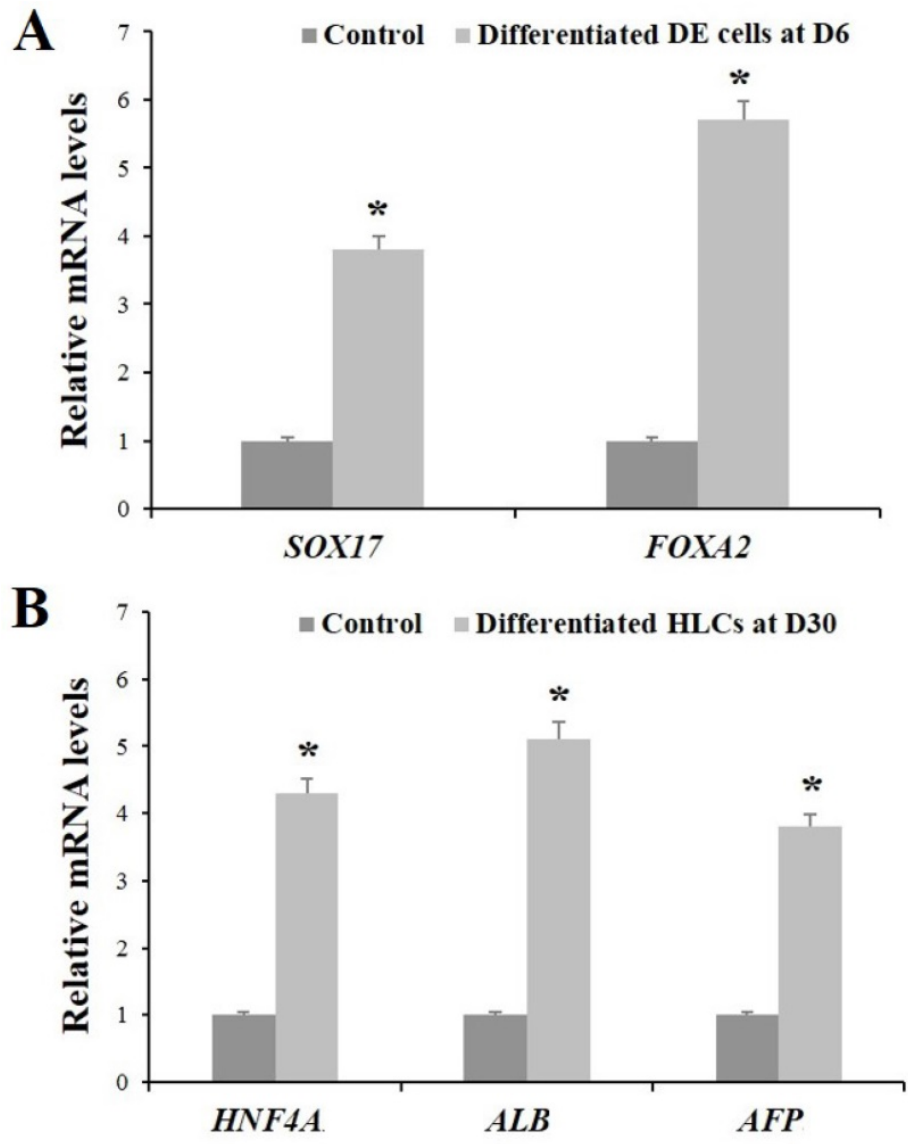

Figure 5. RT-qPCR data for in vitro differentiated cells of definitive endoderm (DE) at D6 and hepatocyte-like cells (HLCs) at D30. (A) Relative mRNA levels for DEand hepatocyte-markers were calculated with the $2^{-\Delta \Delta C t}$ method using YWHAZ for normalization and are expressed as the fold-change relative to the control (undifferentiated hDPSCs-cryo). The differentiated DE cells at D6 and HLCs at D30 showed 4-6-fold higher mRNA levels for their specific markers (SOX17 and FOXA2 for DE; HNF4A1, ALB3 and AFP3 for hepatocyte) compared than those of control. Data represent the mean \pm SD of four independent experiments. Significantly different from control; *, $\mathrm{P}<0.05$ (B) Representative images of RT-PCR products of hDPSCs-cryo group to show product size of (A). Abbreviations: SOX17, sex determining region Y-box 17; FOXA2, forkhead box protein A2 (hepatocyte nuclear factor 3-beta); AFP, alpha-Fetoprotein; ALB, human albumin; HNF4A, hepatonuclear factor 4 alpha; Tyrosine 3-monooxygenease/tryptophan 5-monooxygenease activation protein, zeta polypeptide.

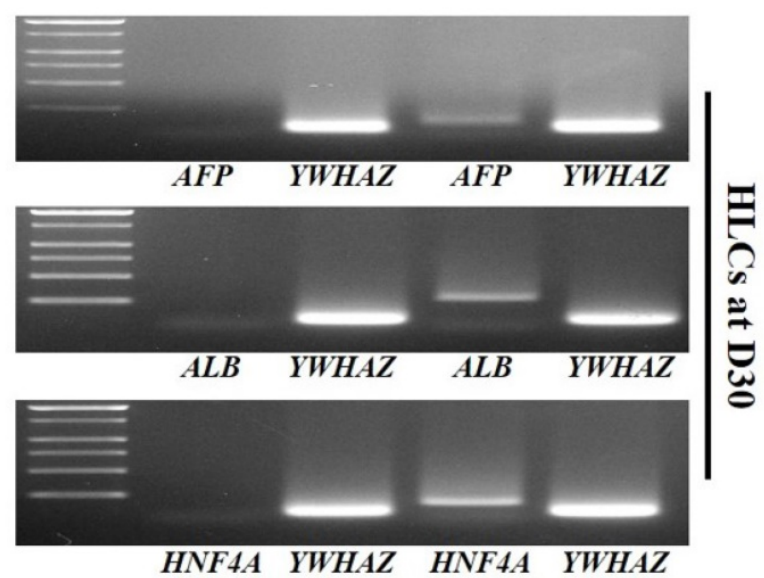

pulp tissues using our newly developed tissue cryopreservation protocol could safely conserve multipotent stem cells, which showed same MSC-characteristics with those derived from fresh dental pulp tissues. hDPSCs-fresh and hDPSCs-cryo showed the same cell morphology, proliferation rate, expression of cell-surface markers, and in vitro differentiation potential as the mesenchymal lineage. Moreover, hDPSCs-cryo successfully differentiated into DE followed by functional hepatocyte-like cells under the two-step induction protocol. Dental pulp originates from the embryonal neural crest, and therefore, the DPSCs will more easily differentiate into multi-lineage cells than MSCs from other sources [6, 14, 16, 17, 20-22]. hDPSCs from exfoliated deciduous teeth (SHED) or adult teeth can successfully differentiate into functional hepatocytes in vitro as well as mesenchymal lineage cells $[2,6$, 19-21].

C

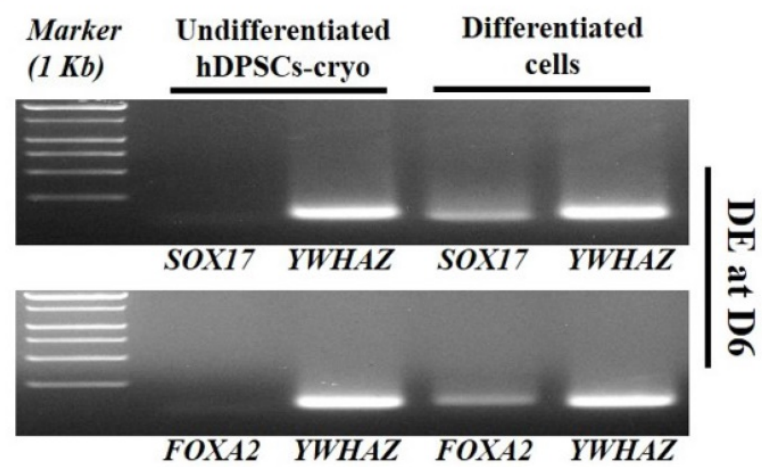


A
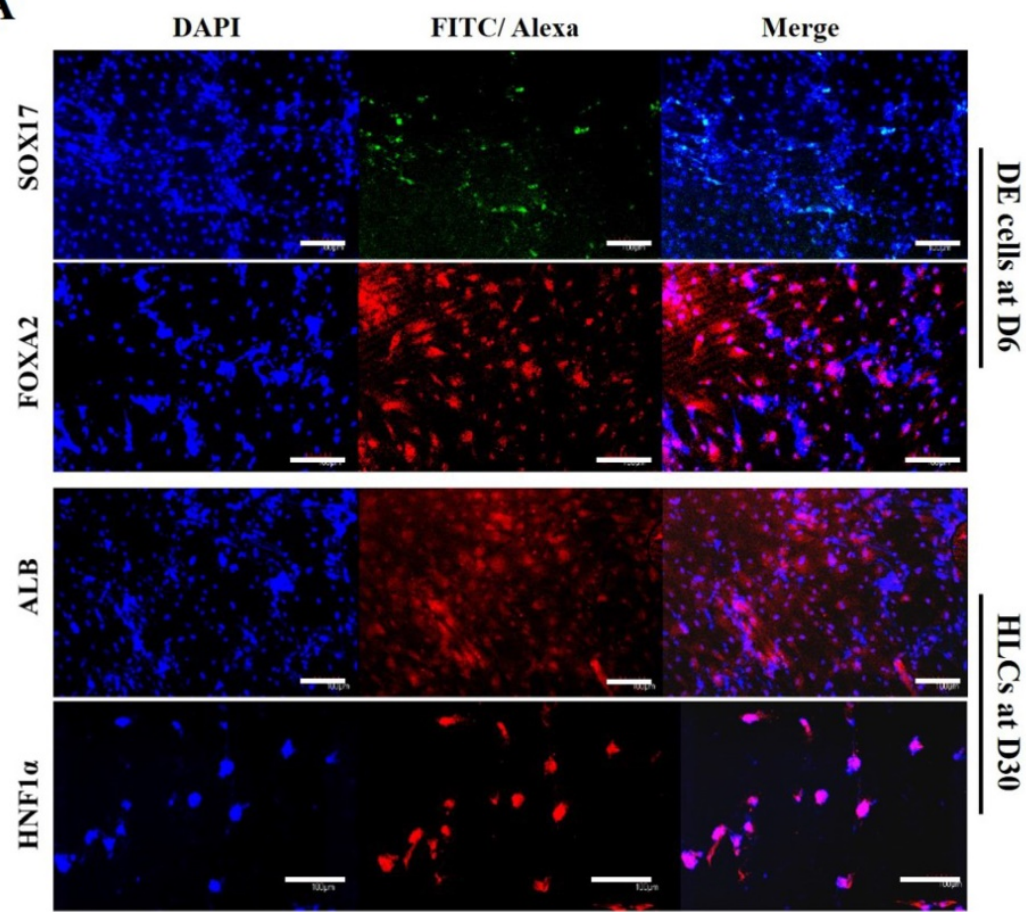

B
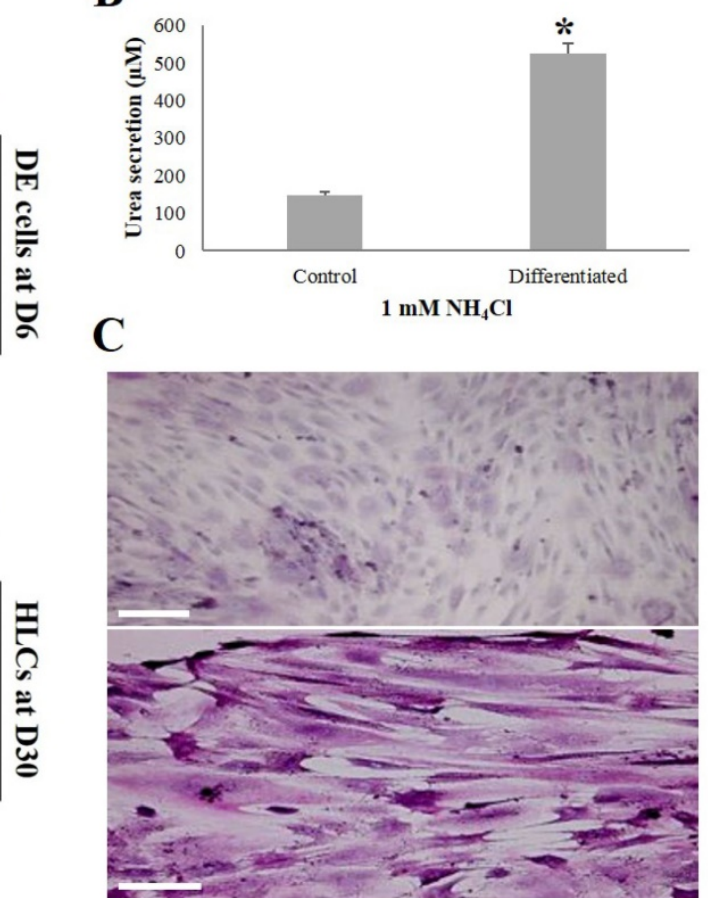

Figure 6. Analyses for the expressions of DE (SOX17 and FOXA2)- and hepatocyte (ALB and HNF1a)-specific proteins, glucose storage ability, and detoxification capacity of the differentiated cells. Scale bar $=50 \mu \mathrm{m}$. (A) The positive nuclear expression of SOX17 and cytoplasmic expression of FOXA2 were detected in the DE-differentiated cells at D6. Similarly, cytoplasmic expression of ALB and nuclear expression of HNFla were strongly observed in the differentiated HLCs at D30. (B) The differentiated HLCs at D30 showed significantly increased urea synthetic ability as a response to exogenous ammonia compared to control (hDPSCs-cryo). Data represent the mean \pm SD of three independent experiments. Significantly different from control; *, p < 0.05 (C) The differentiated HLCs at D30 showed strong PAS staining signal compared than control (almost no signal), indicating HLCs have glucose storage capacity. These results demonstrate that the differentiated HLCs could form functional hepatocytes. Abbreviations: SOX17, sex determining region Y-box 17; FOXA2, forkhead box protein A2 (hepatocyte nuclear factor 3-beta); ALB, human albumin; HNF-1 $\alpha$; hepatocyte nuclear factor 1 -alpha.

Interestingly, SHED has been implicated as an excellent stem cell source for hepatocyte differentiation [6, 19, 20, 27]. SHED showed higher cell proliferation rate and multi-lineage differentiation potential than MSCs from adult teeth [17, 27]. However, harvesting pulp tissue from exfoliated teeth is not easy because of the presence of small remnant tissue. Presently, pulp tissues from extracted adult wisdom teeth were also an excellent stem cell sources. The tissue contains abundant pluripotent progenitor cells from the neural crest, and the material can be easily obtained from people at a relatively late age of about 20 years. In our previous studies, MSCs from adult dental pulps displayed pluripotent characteristics and superior multi-lineage differentiation potential $[12,14]$. Moreover, the dental tissues from extracted wisdom teeth can be safely cryopreserved with our newly developed slow-freezing protocol for use as an autologous stem cell resource without loss of their stemness even after prolonged storage [15].

Several protocols have been introduced for in vitro hepatocyte differentiation from stem cells. These use small molecules or various cytokines and growth factors involved in liver development [5, 6, 23, 28]. However, in embryogenesis, in vivo liver development is a more complex and stepwise sequential procedure. Pluripotent stem cells were collected in the inner cell mass of the epiblasts of embryos. These cells were subsequently fated to become primitive endoderm or epiblast cells. Epiblast cells ingress in the primitive steak to form mesendoderm and DE. Finally, DE cells differentiate into endodermal organs including the pancreas, liver, intestines, and lungs [24, 25, 29]. These properties of endodermal organ development prompted the thought that generation of $\mathrm{DE}$ is an important interphase course during in vitro hepatogenic differentiation from stem cells [24-26]. Other researchers observed successful direct in vitro hepatocyte differentiation from adult stem cells using various growth factors and cytokines related to liver development $[4,6,10,20,21]$.

Human ESCs and MSCs have been successfully differentiated into DE with Activin A and Wnt3a treatment. These cells are ultimately induced to form the functional hepatocytes or pancreatic progenitor cells [24, 25]. Many researchers reported that Nodal/Activin signaling is important in the development of DE from ESCs or MSCs [26, 30, 31]. Activin $\mathrm{A}$ is a member of the transforming growth factor (TGF)- $\beta$ superfamily. It utilizes a signaling mechanism similar to Nodal and SMAD2/3 [26, 32]. 
Activin A induces rapid endodermal differentiation from both ESCs and MSCs [24, 26, 33]. Interestingly, MSCs treated with Activin A might alter their differentiation potential and lose the property of mesodermal differentiation. However, they still express mesendoderm- or ectoderm-related genes [25]. In addition, the Wnt signaling pathway activator, Wnt3a, displays a synergistic effect with Activin A in DE differentiation from ESCs or MSCs [34]. The concomitant use of Wnt3a and Activin A for differentiation of MSCs into DE cells significantly decreases the ectodermal cell population compared to the use of Activin A alone [25]. Consistently, in the present study, MSCs derived from long-term cryopreserved human dental pulp tissues (hDPSCs-cryo) successfully differentiated into DE with Activin A and Wnt3a treatment. The differentiated cells displayed increased DE markers, SOX-17 and FOXA2, at both the mRNA and protein levels. These results demonstrate that DE cells induced from hDPSCs-cryo could be used as a source of cells for the generation of various endodermal cells, including pancreatic, liver, lung, and gut cells.

Interestingly, recent studies reported that undifferentiated stem cells or stem cell culture media have significant curative effects in liver fibrosis animal models after in vivo administration $[1,9,18$, 22]. Intravenous or intraperitoneal administered stem cells homed in to multiple organs, including liver, pancreas, kidney, and lung. Subsequently, these cells directly convert into the target cells and regenerate injured tissues [1, 22, 35]. After in vivo transplantation, stem cells also interact with surrounding host cells, which secrete cytokines and growth factors to bestow curative effects in the damaged organs through the cross-talk mechanism [35]. In addition, stem cell culture media contains multiple tissue regenerating factors, which have roles in anti-apoptosis, hepatocyte protection, angiogenesis, and differentiation of macrophage and liver progenitor cells [18]. A prior study described that in vivo injection of SHED culture medium produced remarkable therapeutic effects in a liver failure animal model, with similar liver recovery effect as observed in the in vivo SHED injection group [18]. However, in vivo transplantation of differentiated hepatocytes from DPSCs shows significant improvement on both acute liver injury and secondary biliary cirrhosis [20]. The remarkable liver protection property and regeneration potential of damaged liver tissues after in vivo administration of differentiated hepatocytes from various stem cells has been demonstrated [1, 36, 37]. Moreover, to generate tissue-engineered total or partial liver organ that could replace the liver transplantation, well-organized and highly effective in vitro hepatocyte differentiation protocol from stem cells is necessary.

In hepatogenic induction of dental pulp stem cells, most studies have used a direct conversion protocol involving various growth factors, such as HGF, oncostatin, and dexamethasone, without confirmation of DE generation [6, 19-21]. However, in the present study, hDPSCs-cryo were first differentiated DE cells in vitro in the presence of Activin A and Wnt3a for 6 days. Then, the induced DEs were further differentiated into hepatoblast-like cells using rhHGF for 7 days, followed by hepatocyte maturation with oncostatin $\mathrm{M}$, dexamethasone, and ITS for a further 17 days. The HLCs induced from hDPSCs-cryo showed abundant expressions of hepatocyte-related mRNA, such as HNF4A, ALB, and $A F P$, and proteins for ALB and HNF-1a. In addition, the induced HLCs showed detoxification capacity as assessed based on urea synthesis response to exogenous ammonia, and glycogen storage ability assessed by PAS positive staining.

To our knowledge, this is the first report of the sequential differentiation into DE and functional hepatocytes in vitro of MSCs derived from adult dental pulps. In particular, the present study demonstrates that long-term preserved dental pulp tissues harvested from the extracted wisdom teeth can be an excellent autologous stem cell source for generation of DE and endodermal cells. Preservation of dental tissues would be worthwhile for use as an autologous stem cell resource in tissue engineering.

\section{Abbreviations}

Hoechst: Hoechst 33342; PI: propidium iodine; CD: cluster of differentiation (classification determinant); hDPSCs: human dental pulp stem cells; hDPSCs-cryo: hDPSCs from cryopreserved dental pulps; hDPSCs-fresh: hDPSCs from fresh dental pulps; PPARy2: peroxisome proliferator activated receptor- $\gamma 2$; LPL: lipoprotein lipase; FABP4: fatty acid binding protein 4; BMP2: bone morphogenetic protein 2; RUX2: runt-related transcription factor 2; ON: osteonectin; SOX9: sex determining region Y-box 9; Aggrecan: cartilage-specific proteoglycan core protein; Collagen II: type II collagen; YWHAZ: Tyrosine 3-monooxygenease/tryptophan 5-monooxygenease activation protein, zeta polypeptide; DE: Definitive endoderm; HLCs: hepatocyte-like cells, SOX17, sex determining region Y-box 17; FOXA2: forkhead box protein A2 (hepatocyte nuclear factor 3-beta); HNF4A: hepatonuclear factor 4 alpha; ALB: human albumin; AFP: alpha-Fetoprotein; HNF-1a: hepatocyte nuclear factor 1-alpha; PAS staining: Periodic Acid-Schiff staining. IBMX: isobutylmethylxanthine; ITS-mix: insulin- 
transferrin-selenium mix; Wnt3a: Wnt signaling pathway activator; rhHGF: recombinant human hepatocyte growth factor; SHED: dental pulp stem cells from human exfoliated deciduous teeth.

\section{Acknowledgement}

This work was supported by the National Research Foundation of Korea (NRF) Grant funded by the Korean Government (NRF2016R1D1A3B03932491).

\section{Authors' contributions}

Young-Jin Han and Sarath Belame Shivakumar designed study, perfomed data analysis, and contributed to the manuscript preparation. Yong-Ho Choi, Dinesh Bharti, Young-Bum Son, and Won-Uk Park performed cell culture and in vitro hepatogenic differentiation experiments. Young-Hoon Kang and June-Ho Byun collected the extracted wisdom teeth, participated in the statistical analysis. Gyu-Jin Rho and Bong-Wook Park made contributions to the management of all the experiments, analysis of the collected data, and were major contributors to the manuscript preparation. All the authors read and approved the final manuscript.

\section{Competing Interests}

The authors have declared that no competing interest exists.

\section{References}

1. Manzini BM, da Silva Santos Duarte A, Sankaramanivel S, Ramos AL, Latuf-Filho P, Escanhoela C, et al. Useful properties of undifferentiated mesenchymal stromal cells and adipose tissue as the source in liver-regenerative therapy studied in an animal model of severe acute fulminant hepatitis. Cytotherapy. 2015;17(8):1052-65.

2. Ohkoshi S, Hara H, Hirono H, Watanabe K, Hasegawa K. Regenerative medicine using dental pulp stem cells for liver diseases. World J Gastrointest Pharmacol Ther. 2017;8(1):1-6.

3. Lee KD, Kuo TK, Whang-Peng J, Chung YF, Lin CT, Chou SH, et al. In vitro hepatic differentiation of human mesenchymal stem cells. Hepatology. 2004;40(6):1275-84.

4. Seo MJ, Suh SY, Bae YC, Jung JS. Differentiation of human adipose stromal cells into hepatic lineage in vitro and in vivo. Biochem Biophys Res Commun. 2005;328(1):258-64.

5. Cai J, Zhao Y, Lui Y, Ye F, Song Z, Qin H, et al. (2007) Directed differentiation of human embryonic stem cells into functional hepatic cells. Hepatology. 2007;45(5):1229-39.

6. Ishkitiev N, Yaegaki K, Calenic B, Nakahara T, Ishikawa H, Mitiev V, Haapasalo M. Deciduous and permanent dental pulp mesenchymal cells acquire hepatic morphologic and functional features in vitro. J Endod. 2010;36(3):469-74.

7. Yu J, Cao H, Yang J, Pan Q, Ma J, Li J, et al. In vivo hepatic differentiation of mesenchymal stem cells from human umbilical cord blood after transplantation into mice with liver injury. Biochem Biophys Res Commun. 2012;422(4):539-45.

8. Talaei-Khozani T, Borhani-Haghighi M, Ayatollahi M, Vojdani Z. An in vitro model for hepatocyte-like cell differentiation from Wharton's jelly derived-mesenchymal stem cells by cell-base aggregates. Gastroenterol Hepatol Bed Bench. 2015;8(3):188-99.

9. Chen Z, Kuang Q, Lao XJ, Yang J, Uang W, Zhou D. Differentiation of UC-MSCs into hepatocyte-like cells in partially hepatectomized model rats. Exp Ther Med. 2016:12(3):1775-79.

10. Shivakumar SB, Bharti D, Subbarao RB, Jang SJ, Par JS, Ullah I, et al. DMSOand serum-free cryopreservation of Wharton's jelly tissue isolated from human umbilical cord. J Cell Biochem. 2016;117(10):2397-412.

11. Jeon BG, Kang EJ, Kumar BM, Maeng GH, Ock SA, Kwack DO, et al. Comparative analysis of telomere length, telomerase and reverse transcriptase activity in human dental stem cells. Cell Transplant. 2011;20(11-12):1693-705.
12. Patil R, Kumar BM, Lee WJ, Jeon RH, Jang SJ, Lee YM, et al. Multilineage potential and proteomic profiling of human dental stem cells derived from a single donor. Exp Cell Res. 2014;320(1):91-107.

13. Kang YH, Lee HJ, Jang SJ, Byun JH, Lee JS, Lee HC, et al. Immunomodulatory properties and in vivo osteogenesis of human dental stem cells from fresh and cryopreserved dental follicles. Differentiation. 2015;90(1-3):48-58.

14. Ullah I, Subbarao RB, Kin EJ, Bharti D, Jang SJ, Park JS, et al. In vitro comparative analysis of dental stem cells from a single donor and its neuronal differentiation potential evaluated by electrophysiology. Life Sci. 2016; 154:39-51.

15. Park BW, Jang SJ, Byun JH, Kang $\mathrm{YH}$, Choi MJ, Park WU, et al. Cryopreservation of human dental follicle tissue for use as a resource of autologous mesenchymal stem cells. J Tissue Eng Reg Med. 2017;11(2):489-500.

16. Gronthos S, Mankani M, Brahim J, Robey PG, Shi S. Postnatal human dental pulp stem cells (DPSCs) in vitro and in vivo. Proc Natl Acad Sci U S A. 2000;97(25):13625-30.

17. Miura M, Gronthos S, Zhao M, Lu B, Fisher LW, Robey PG, Shi S. SHED: stem cells from human exfoliated deciduous teeth. Proc Natl Acad Sci U S A. 2003;100(10):5807-12

18. Matsushita $\mathrm{Y}$, Ishigami M, Matsubara $\mathrm{K}$, Kondo M, Wakayama H, Goto H, et al. Multifaceted therapeutic benefits of factors derived from stem cells from human exfoliated deciduous teeth for acute liver failure in rats. J Tissue Eng Regen Med. 2017;11(6):1888-96.

19. Okada $\mathrm{M}$, Ishkitiev $\mathrm{N}$, Yaegaki $\mathrm{K}$, Imai $\mathrm{T}$, Tanaka $\mathrm{T}$, Fukuda $\mathrm{M}$, et al. Hydrogen sulphide increases hepatic differentiation of human tooth pulp stem cells compared with human bone marrow stem cells. Int Endo J. 2014;47(12):1142-50.

20. Ishkitiev N, Yaegaki K, Imai T, Tanaka T, Fushimi N, Mitev V, et al. Novel management of acute or secondary biliary liver conditions using hepatically differentiated human dental pulp cells. Tissue Eng Part A. 2015;21(3-4):586-93.

21. Kim HJ, Cho YA, Lee YM, Lee SY, Bae WJ, Kim EC. PIN1 suppresses the hepatic differentiation of pulp stem cells via Wnt3a. J Dent Res. 2016;95(12):1415-24.

22. Yamaza T, Alatas FS, Yuniartha R, Yamaza H, Fujiyoshi JK, Yanagi Y, et al. In vivo hepatogenic capacity and therapeutic potential of stem cells from human exfoliated deciduous teeth in liver fibrosis in mice. Stem Cell Res Ther. 2015; 6:171.

23. Tasnim F, Phan D, Toh YC, Yu H. Cost-effective differentiation of hepatocyte-like cells from human pluripotent stem cells using small molecules. Biomaterials. 2015; 70:115-25.

24. Roelandt P, Pauwelyn KA, Sancho-Bru P, Subramanian K, Bose B, Ordovas L, et al. Human embryonic and rat adult stem cells with primitive endoderm-like phenotype can be fated to definitive endoderm, and finally hepatocyte-like cells. PLoS One. 2010; 5(8e):12101.

25. Li J, Zhu L, Qu X, et al. Stepwise differentiation of human adipose-derived mesenchymal stem cells toward definitive endoderm and pancreatic progenitor cells by mimicking pancreatic development in vivo. Stem Cells Dev. 2013;22(10):1576-87.

26. Lee SW, Min SO, Bak SY, Hwang HK, Kim KS. Efficient endodermal induction of human adipose stem cells using various concentration of Activin A for hepatic differentiation. Biochem Biophys Res Commun. 2015;464(4):1178-84.

27. Rosa V, Dubey N, Islam I, Min KS, Nör JE. Pluripotency of stem cells from human exfoliated deciduous teeth for tissue engineering. Stem Cells Int. 2016; 2016:5957806.

28. Gouon-Evans V, Boussemart L, Gadue P, Nierhoff D, Koehler CI, Koehler CI, et al. BMP-4 is required for hepatic specification of mouse embryonic stem cell derived definitive endoderm. Nat Biotechnol. 2006;24(11):1402-11.

29. Beddington RS, Robertson EJ. Axis Development and Early Asymmetry in Mammals. Cell. 1999;96(2):195-209.

30. Zhang D, Jiang W, Liu M, Sui X, Yin X, Chen S, et al. Highly efficient differentiation of human ES cells and iPS cells into mature pancreatic insulin-producing cells. Cell Res. 2009;19(4):429-38.

31. Tateishi K, He J, Taranova O, Liang G, D'Alessio AC, Zhang Y. Generation of insulin-secreting islet-like clusters from human skin fibroblasts. J Biol Chem 2008;283(46):31601-7.

32. Clotman F, Lemaigre FP. Control of hepatic differentiation by activing/TGF beta signaling. Cell Cycle. 2006;5(2):168-71.

33. Parashurama N, Nahmias $\mathrm{Y}$, Cho $\mathrm{CH}$, van Poll $\mathrm{D}$, Tilles AW, Berthiaume $\mathrm{F}$, et al. Activin alters kinetics of endoderm induction in embryonic stem cells cultured on collagen gels. Stem Cells. 2008;26(2):474-84.

34. Gadue P, Huber TL, Paddison PJ, Keller GM. Wnt and TGF-beta signaling are required for the induction of an in vitro model of primitive streak formation using embryonic stem cells. Proc Natl Acad Sci U S A. 2006;103(45):16806-11.

35. Seong IY, Son HN, Ullah I, Bharti D, Park JM, Cho YC, et al. Cardiomyogenic differentiation of human dental follicle-derived stem cells by suberylanilide hydroxamic acid and their in vivo homing property. Int $\mathrm{J}$ Med Sci. 2016;13(11):841-852.

36. Tolosa L, Caron J, Hannoun $\mathrm{Z}$, Antoni M, López S, Burks $\mathrm{D}$, et al. Transplantation of hESC-derived hepatocytes protects mice from liver injury. Stem Cell Res Ther. 2015; 6:246

37. Ramanathan R, Pettinato G, Beeston JT, Lee DD, Wen X, Mangino MJ, et al. Transplantation of human stem cell-derived hepatocytes in an animal model of acute liver failure. Surgery. 2015;158(2):349-59. 